\title{
Index to Volume 5
}

Adler, R. L., Kitchens, B. AND MARCus, B. H. Finite group actions on shifts of finite type, 1

AdleR, R., Kitchens, B. AND MARCuS, B. Almost topological classification of finite-to-one factor maps between shifts of finite type, 485

AlsedÀ, L., Llibre, J., Misiurewicz, M. ANd Simó, C. Twist periodic orbits and topological entropy for continuous maps of the circle of degree one which have a fixed point, 501

BAKER, I. N. Some entire functions with multiply-connected wandering domains, 163

BAtTERSon, S. AND Smillie, J. Smale diffeomorphisms and surface topology, 519

BATTY, C. J. K. AND ROBINSON, D. W. The characterization of differential operators by locality: abstract derivations, 171

BERNSTEIN, D. Birkhoff periodic orbits for twist maps with the graph intersection property, 531

BLOCK, L. AND FRANKE, J. E. The chain recurrent set, attractors, and explosions, 321

BOYD, C. On the structure of the family of Cherry fields on the torus, 27

BURNS, K. AND KATOK, A. Manifolds with non-positive curvature, 307

Calderoni, P., Campanino, M. and Capocaccia, D. A local limit theorem for a sequence of interval transformations, 185

Campanino, M. See Calderoni, P. et al.

Capocaccia, D. See Calderoni, P. et al.

ConNes, A. AND Woods, E. J. Approximately transitive flows and ITPFI factors, 203

Franke, J. E. See Block, L. ANd Franke, J. E.

FrIED, D. Growth rate of surface homeomorphisms and flow equivalence, 539

Ghys, E., Goldberg, L. R. ANd Sullivan, D. P. On the measurable dynamics of $z \mapsto e^{z}, 329$

Giordano, T. AND SKandalis, G. On infinite tensor products of factors of type $I_{2}, 565$

GoldberG, L. R. See GHYS, E. et al.

Golodets, V. YA. AND SinelshChikov, S. D. Locally compact groups appearing as ranges of cocycles of ergodic Z-actions, 47

GoROFF, D. L. Hyperbolic sets for twist maps, 337

Grebogi, C., OTt, E. AND Yorke, J. A. Super persistent chaotic transients, 341

HANDEL, M. Global shadowing of pseudo-Anosov homeomorphisms, 373

Hofbauer, F. Periodic points for piecewise monotonic transformations, 237

HURDer, S. Problems on rigidity of group actions and cocycles, 473

IM HoF, H.-C. An Anosov action on the bundle of Weyl chambers, 587

DEL JUNCO, A. AND KEANE, M. On generic points in the Cartesian square of Chacón's transformation, 59

Katok, A. See Burns, K. AND Katok, A.

Keane, M. See del Junco, A. And KeAne, M.

KERCKHOFF, S. P. Simplicial systems for interval exchange maps and measured foliations, 257

KING, J. A counterexample to a positive entropy skew product generalization of the Pinsker conjecture, 379

Kitchens, B. See ADler, R. et al. (twice)

KRAWCZAK, M. On upcrossing inequalities for subadditive superstationary processes, 409

Ledrappier, F. AND Misiurewicz, M. Dimension of invariant measures for maps with exponent zero, 595

Llibre, J. See AlsedÀ, L. et al. 
MAÑE, R. On the Bernoulli property for rational maps, 71

MANNING, A. Errata to 'Hausdorff dimension for horseshoes', 319

Marcus, B. See AdLer, R. et al. (twice)

MENDOZA, L. The entropy of $C^{2}$ surface diffeomorphisms in terms of Hausdorf dimension and a Lyapunov exponent, 273

Misiurewicz, M. See AlsedÀ, L. et al.

Misiurewicz, M. See Ledrappier, F. ANd Misiurewicz, M.

MOECKEL, R. Relative equilibria of the four-body problem, 417

NASU, M. An invariant for bounded-to-one factor maps between transitive sofic shifts, 89

NowICKI, T. Symmetric $S$-unimodal mappings and positive Liapunov exponents, 611

OTt, E. See Grebogl, C. et al.

Robinson, D. W. See Batty, C. J. K. And Robinson, D. W.

Robinson, E. A. Mixing and spectral multiplicity, 617

ROCHA, L. F. C. Characterization of Morse-Smale isotopy classes on surfaces, 107

RUDNICKI, R. Invariant measures for the flow of a first order partial differential equation, 437

RudOLPH, D. J. $k$-fold mixing lifts to weakly mixing isometric extensions, 445

RYBAKOWSKI, K. P. AND ZEHNDER, E. A Morse equation in Conley's index theory for semiflows on metric spaces, 123

Shub, M. AND Sullivan, D. Expanding endomorphisms of the circle revisited, 285

Simó, C. See ALSEDÀ, L. et al.

Sinelshchikov, S. D. See Golodets, V. Ya. ANd Sinelshchikov, S. D.

Skandalis, G. See Giordano, T. and Skandalis, G.

Smillie, J. See Batterson, S. and Smillie, J.

Sulljvan, D. See Shub, M. ANd Sullivan, D.

Sullivan, D. P. See Ghys, E. et al.

WACKER, U. On non-additive processes, 291

WoJTkowSKI, M. Invariant families of cones and Lyapunov exponents, 145

WoOds, E. J. See ConNes, A. AND Woods, E. J.

YomDin, Y. A quantitative version of the Kupka-Smale theorem, 449

Yorke, J. A. See Grebogi, C. et al.

Zehnder, E. See Rybakowski, K. P. And Zehnder, E.

ZIEMIAN, K. Almost sure invariance principle for some maps of an interval, 625

ZIMMER, R. J. Actions of lattices in semisimple groups preserving a $G$-structure of finite type, 301 